\title{
Trends in autumn rain of West China from 1961 to 2014
}

\author{
Chi Zhang ${ }^{1,2,3} \cdot$ Zunya Wang $^{2} \cdot$ Botao Zhou ${ }^{1,2}$ (D) $\cdot$ Yonghua $\mathrm{Li}^{3} \cdot$ Hongyu Tang $^{3} \cdot$ Bo Xiang $^{3}$
}

Received: 24 May 2017 / Accepted: 25 December 2017 / Published online: 5 February 2018

(C) The Author(s) 2018. This article is an open access publication

\begin{abstract}
Autumn rain of West China is a typical climate phenomenon, which is characterized by continuous rainy days and large rainfall amounts and exerts profound impacts on the economic society. Based on daily precipitation data from 524 observation stations for the period of 1961-2014, this article comprehensively examined secular changes in autumn rain of West China, including its amount, frequency, intensity, and associated extremes. The results generally show a significant reduction of rainfall amount and rainy days and a significant enhancement of mean rainfall intensity for the average of West China during autumn (SeptemberOctober) since 1961. Meanwhile, decreasing trends are consistently observed in the maximum daily rainfall, the longest consecutive rainy days, the greatest consecutive rainfall amount, and the frequencies of the extreme daily rainfall, consecutive rainfall, and consecutive rainfall process. Further analysis indicates that the decreases of autumn rainfall and related extremes in West China are associated with the decreases in both water vapor content and atmospheric unstable stratification during the past decades. On the regional scale, some differences exist in the changes of autumn rainfall between the eastern and western parts of West China. Besides, it is found that the autumn rainy season tends to start later and terminate earlier particularly in eastern West China.
\end{abstract}

\section{Introduction}

The Intergovernmental Panel on Climate Change (IPCC 2013) in its Fifth Assessment Report demonstrated from multiple lines of evidence that there is an unequivocal warming of the climate system since the second half of the twentieth century. Under the background of global warming, significant changes can be detected in precipitation and its extremes over a wide range of regions (e.g., Easterling et al. 2000; Frich et al. 2002; Yan et al. 2002; Alexander et al. 2006; Min et al. 2011; Rusticucci 2012; Orlowsky and Seneviratne 2012; IPCC 2013; Kruger and Sekele 2013). Precipitation changes

Botao Zhou

zhoubt@cma.gov.cn

1 Collaborative Innovation Center on Forecast and Evaluation of Meteorological Disasters, Nanjing University of Information Science \& Technology, Nanjing 210044, China

2 National Climate Center, China Meteorological Administration, Beijing, China

3 Climate Center of Chongqing Municipality, Chongqing, China accompanied with the warming exert profound impacts on the sustainable development of economic society and thus are highly concerned by the scientific community, policy makers, and the public.

China is also vulnerable particularly to severe droughts and heavy floods resulting from anomalous precipitation, so changes of China's precipitation in a warmer climate are of particular interest and concern. Up till now, there have been numerous researches into this issue and great progress has been made. For example, it has been well documented that there are significant upward trends in annual mean precipitation over Southwest, Northwest, and Eastern China and significant downward trends over central North and Northeast China during the past decades (Liu et al. 2005; Yao et al. 2008; Wang et al. 2012; Wang et al. 2017). The extreme precipitation and its ratio to mean precipitation have also enhanced remarkably in a large area of China, particularly in Northwestern and Eastern China (Zhai et al. 2005; Bai et al. 2007; Feng et al. 2007; Wang et al. 2012; Sun and Ao 2013; Wu et al. 2015; Zhou et al. 2016). Meanwhile, a decrease in rainy days has been observed over most regions (Zhai et al. 1999, 2005; Liu et al. 2005; Qian et al. 2007; You et al. 2008; Zhou et al. 2016). 


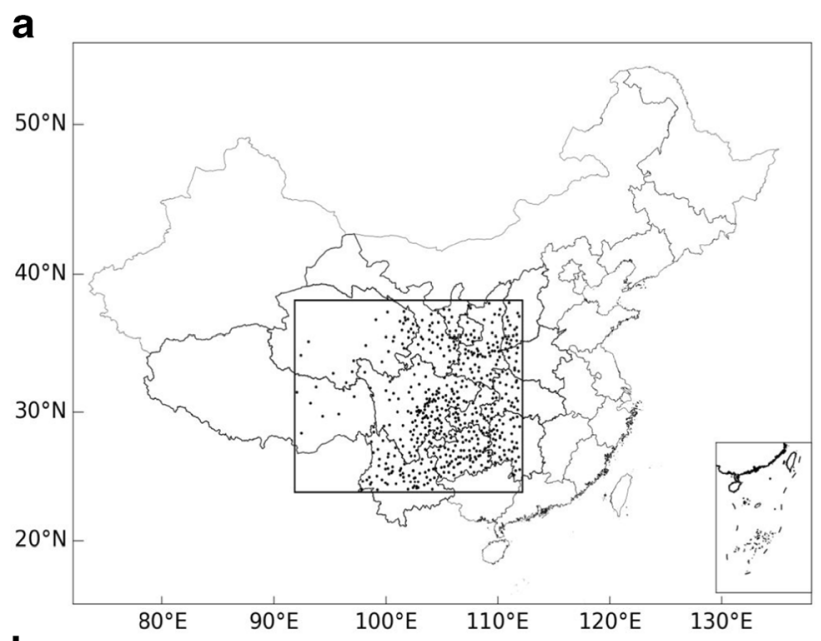

b

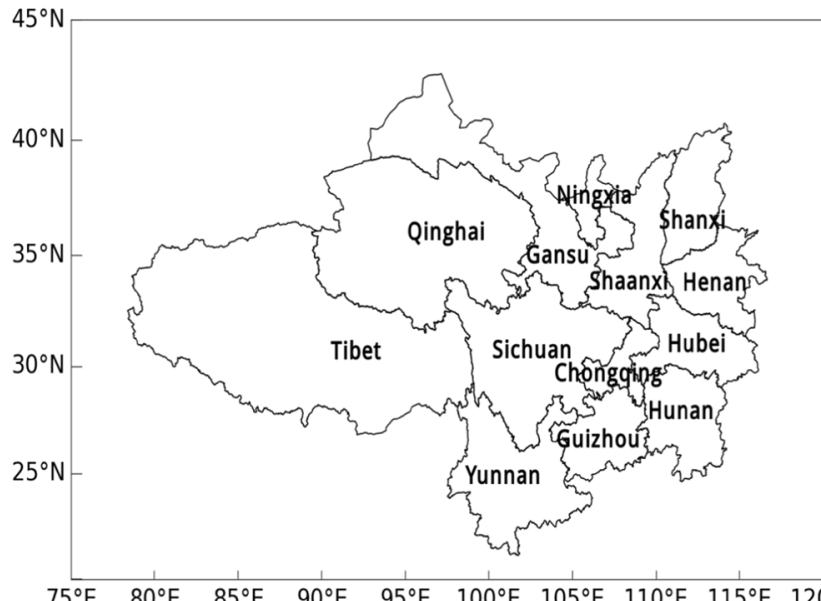

Fig. 1 Distribution of a stations and $\mathbf{b}$ provinces located in West China

Another feature related to precipitation changes in China is the interdecadal variation of summer precipitation pattern. In the late 1970s, the summer precipitation shifted from belownormal to above-normal in the Yangtze River valley, concurrent with less precipitation in North China ( $\mathrm{Wu}$ and Chen
1998; Gong and Ho 2002; Ding et al. 2008; Qian and Qin 2008; Zhang et al. 2009; Zhao et al. 2010; Wang et al. 2013). After entering the twenty-first century, precipitation begins to increase over the Huang-Huai River valley and somewhat decrease over the Yangtze River valley (Zhu et al. 2011). One more transition from dry phase to wet phase in the early 1990s in South China has also been highlighted (Wu et al. 2010; Fan et al. 2014; Xu et al. 2015).

In general, these studies have largely improved our understanding on China's precipitation change in the context of global warming. They, however, mostly focused on changes in annual or summer precipitation and less attention has been paid to autumn precipitation. As is known, autumn precipitation occurring in West China is a typical climate phenomenon, which is named "autumn rain of West China" and similar to Masika and Vuli in East Africa (Camberlin and Philippon 2002) and postChangma in Korea (Wang et al. 2007). The autumn rain of West China usually occurs in September-October, and its rainfall amount is registered as the second peak of local precipitation. In fact, autumn rain of West China is not a local phenomenon but an important component of the main rain belt of China that is linked to the advance and retreat of the East Asian summer monsoon (Ding 2007; Ding and Wang 2008). It not only leads to floods and secondary disasters but also exerts severely adverse impacts on agriculture. Therefore, we are eager to know secular changes of autumn rain of West China in a global warming environment, which is of great significance for climate change adaptation and disaster prevention and mitigation. As such, this study is motivated to investigate its changes in recent decades, with the aim to provide much more detailed information for climate change.

The remainder of this paper is organized as follows. Section 2 describes the data and methods used in this study. The spatiotemporal changes in the amount, frequency, and
Fig. 2 Time series and corresponding linear trend of rainfall amount, rainy day, and rainfall intensity averaged over West China during autumn of 1961-2014

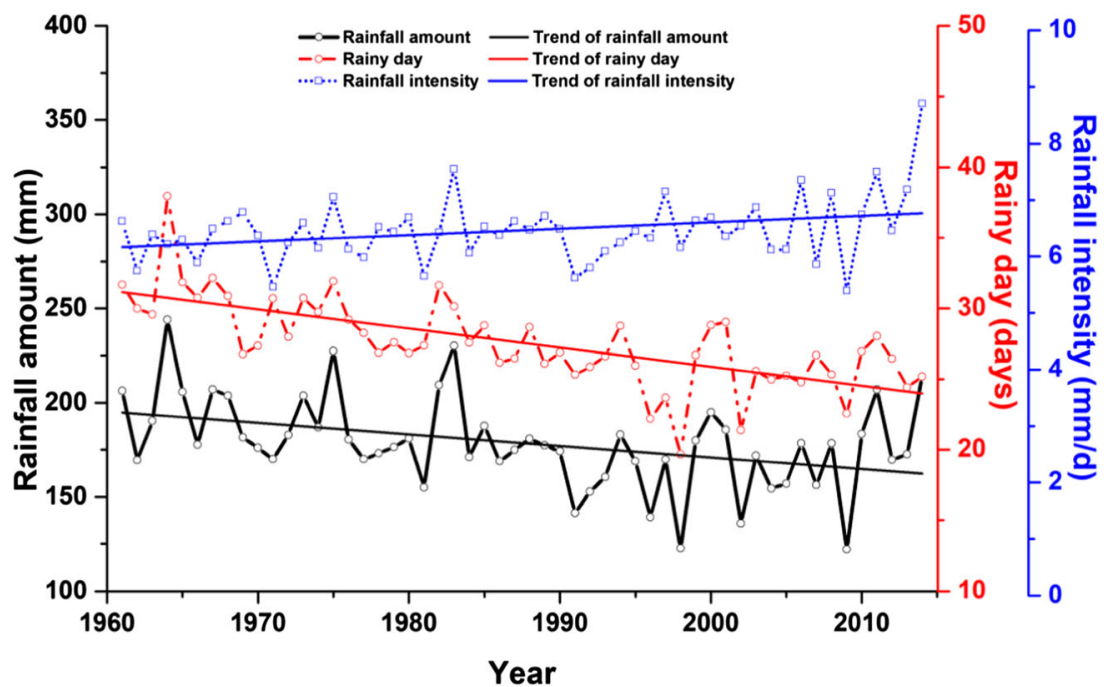




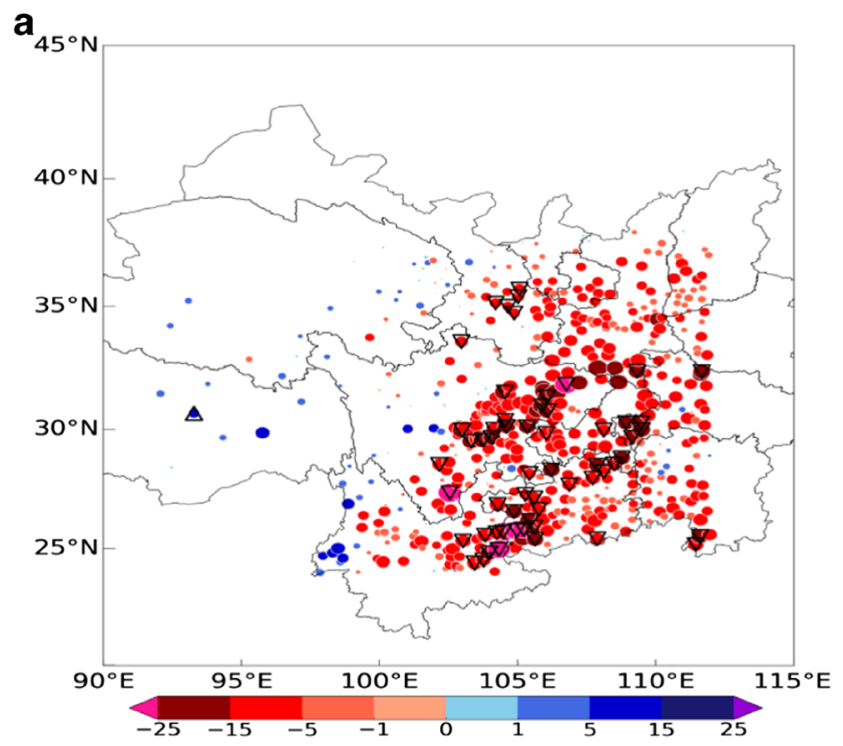

4 Fig. 3 Linear trends of a rainfall amount ( $\mathrm{mm} / 10$ years), b rainy day (days/10 years), and $\mathbf{c}$ rainfall intensity ( $\mathrm{mm} /$ day/10 years) during autumn of 1961 to 2014 for each station of West China. Trends significant at the $95 \%$ confidence level are marked by triangles

intensity of autumn precipitation as well as the onset and termination date of autumn rainy season in West China are presented in Section 3, followed by changes of the precipitationrelated extremes in Section 4. Related discussion and conclusion are finally given in Section 5 and Section 6, respectively.

\section{Data and methods}

The precipitation data used are gauged daily precipitation records from 2400 meteorological stations for the period of 1961-2014. They were compiled by the National Meteorological Information Center, China Meteorological Administration, and have been quality controlled for homogeneity. In this study, the years in which the records of September to October are no more than 50 days were excluded firstly for each station. Then, the stations with records less than 30 years were eliminated. For the remaining stations, the missing daily records were filled by climatological values of daily precipitation during 1961-2014. The target region: West China (outlined by the rectangle in Fig. 1a) is confined to $24^{\circ}$ $38^{\circ} \mathrm{N}, 92-112^{\circ}$ E. It covers 524 stations located in 13 provinces (Tibet, Sichuan, Chongqing, Guizhou, Yunnan, Gansu, Qinghai, Shaanxi, Ningxia, Hunan, Hubei, Henan and Shanxi; see Fig. $1 \mathrm{~b}$ for their locations). Autumn refers to SeptemberOctober, the main time period for the occurrence of autumn rain of West China. Additionally, atmospheric reanalysis data with a horizontal resolution of $2.5^{\circ} \times 2.5^{\circ}$ from the National Centers for Environmental Prediction/National Center for Atmospheric Research (NCEP/NCAR) (Kalnay et al. 1996) are also used.

The day with daily precipitation amount no less than $0.1 \mathrm{~mm}$ is taken as one rainy day. The rainfall intensity is defined as the total precipitation amount divided by the number of rainy days in autumn. As autumn rain of West China is characterized by consecutive rainy days, we selected persistent precipitation process to measure the start and end of autumn rainy season. If the consecutive rainfall persists no less than 2 days, it is regarded as one precipitation process. To ensure the completeness of precipitation process, when one precipitation process cut across either the beginning of September or the end of October, it is extended correspondingly to the end of August or to the beginning of November. The beginning (ending) day of autumn rainy season in West China is defined as the first (last) day of the first (last) precipitation process in autumn. The threshold to define extreme daily precipitation is determined based on the 90th percentile of total samples of daily precipitation, and that to define 
Fig. 4 Time series and corresponding linear trend of the beginning day and the ending day of autumn rain of West China

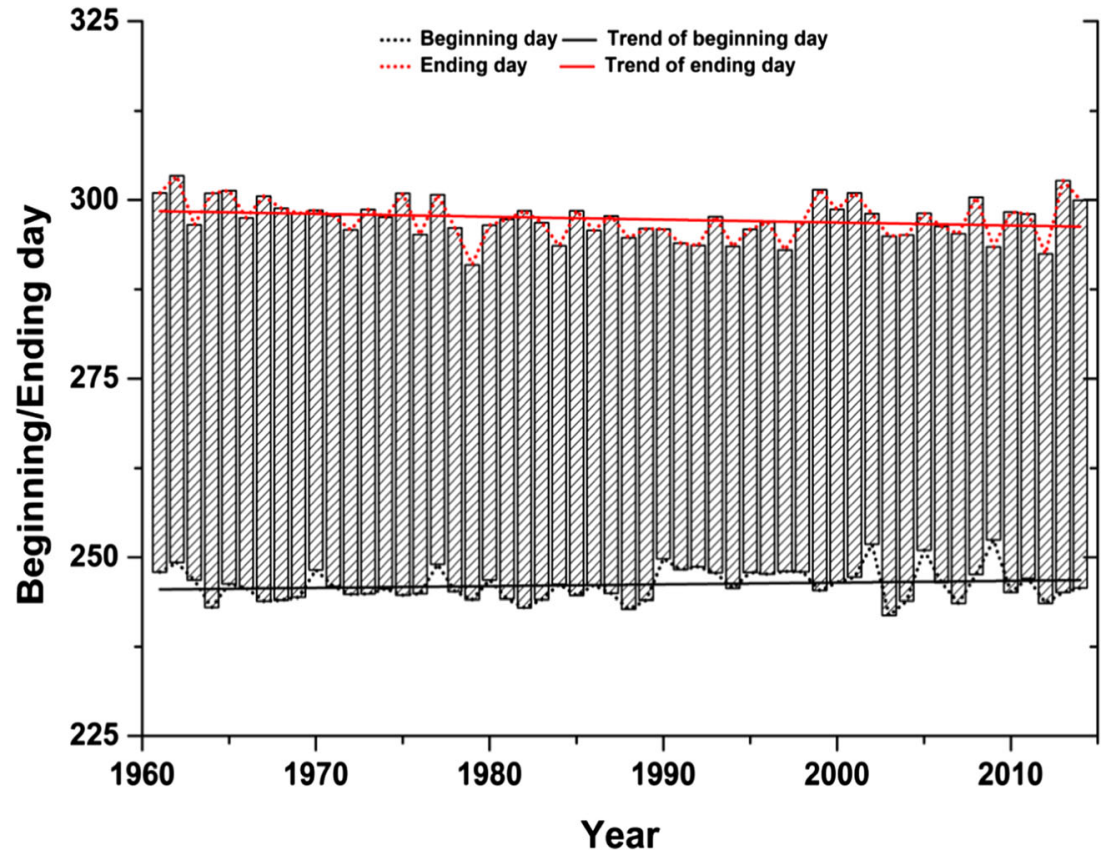

extreme consecutive rainy days (rainfall amounts) is determined based on the 80th percentile of total samples.

In the present study, we focus on trends in the change of autumn rain of West China from 1961 to 2014. The linear trends are calculated with the least square method and the correlation factors test for their significance with the $t$ test.

\section{Changes of autumn precipitation in West China}

\subsection{Rainfall amount, frequency, and intensity}

Figure 2 shows the temporal evolution of the amount, frequency, and intensity of autumn rainfall averaged over West China during 1961-2014. As shown in the figure, a salient decrease is observed in both rainfall amount and rainfall frequency. In the last 54 years, the autumn rainfall amount has decreased by $33.0 \mathrm{~mm}$ (at a rate of $-6.1 \mathrm{~mm}$ per decade), and the number of rainy days has reduced by 7.6 days (at a rate of -1.4 days per decade). Such decreasing trends are both significant at the $95 \%$ confidence level. In contrast to changes of the rainfall amount and frequency, the rainfall intensity exhibits a notable increasing trend at a rate of $0.11 \mathrm{~mm} /$ day per decade (significant at the $95 \%$ confidence level). The coherent downward trends between the rainfall amount and frequency while opposite trends between the rainfall amount and intensity suggest that the decrease in total precipitation amount mainly results from the decrease in rainfall frequency. Further investigation implies that the largest contribution to the decrease of rainfall frequency is from the change in rainfall events with daily precipitation ranging from 0.1 to $1 \mathrm{~mm}$, which have decreased at a rate of $8.6 \%$ per decade (significant at the $95 \%$ confidence level) since the 1960s. This kind of rainfall has little contribution to the change in rainfall amount, but may have a great impact on the change in mean rainfall intensity.

To further explore their regional features, we present the distribution of linear trends of the rainfall amount, frequency, and intensity over each station of West China during the same period. For the change of rainfall amount (Fig. 3a), it is in general characterized by a decrease in the eastern part and an increase in the western part. To the east of $100^{\circ} \mathrm{E}$ in West China, there are 414 stations with the trends below $-1 \mathrm{~mm}$ per decade. To the west of $100^{\circ} \mathrm{E}$ in West China, 30 stations show increasing trends in the range of 0.03 to $11.2 \mathrm{~mm}$ per decade.

Compared with the rainfall amount change, the reduction in the number of rainy days is more widespread across West China (Fig. 3b). Since 1961, the rainy days have reduced by 0.5 to 20 days in a widespread region of West China. Moreover, the decreasing trends are mostly significant above the $95 \%$ confidence level.

Changes in rainfall intensity over West China are more heterogeneous in spatial distribution (Fig. 3c) than that for the rainfall amount and frequency. Totally, 264 stations show a strengthening trend above $0.1 \mathrm{~mm} /$ day per decade, and 68 stations exhibit a weakening trend below $-0.1 \mathrm{~mm} /$ day per decade. The remaining 192 stations present no appreciable changes in the range of -0.1 to $0.1 \mathrm{~mm} /$ day per decade.

Through the comparison of Fig. $3 \mathrm{a}$ with Fig. $3 \mathrm{~b}$ and Fig. 3c, it can be derived that the decrease of rainfall amount over eastern West China is primarily due to the decrease in rainfall frequency, since the trends of rainfall 


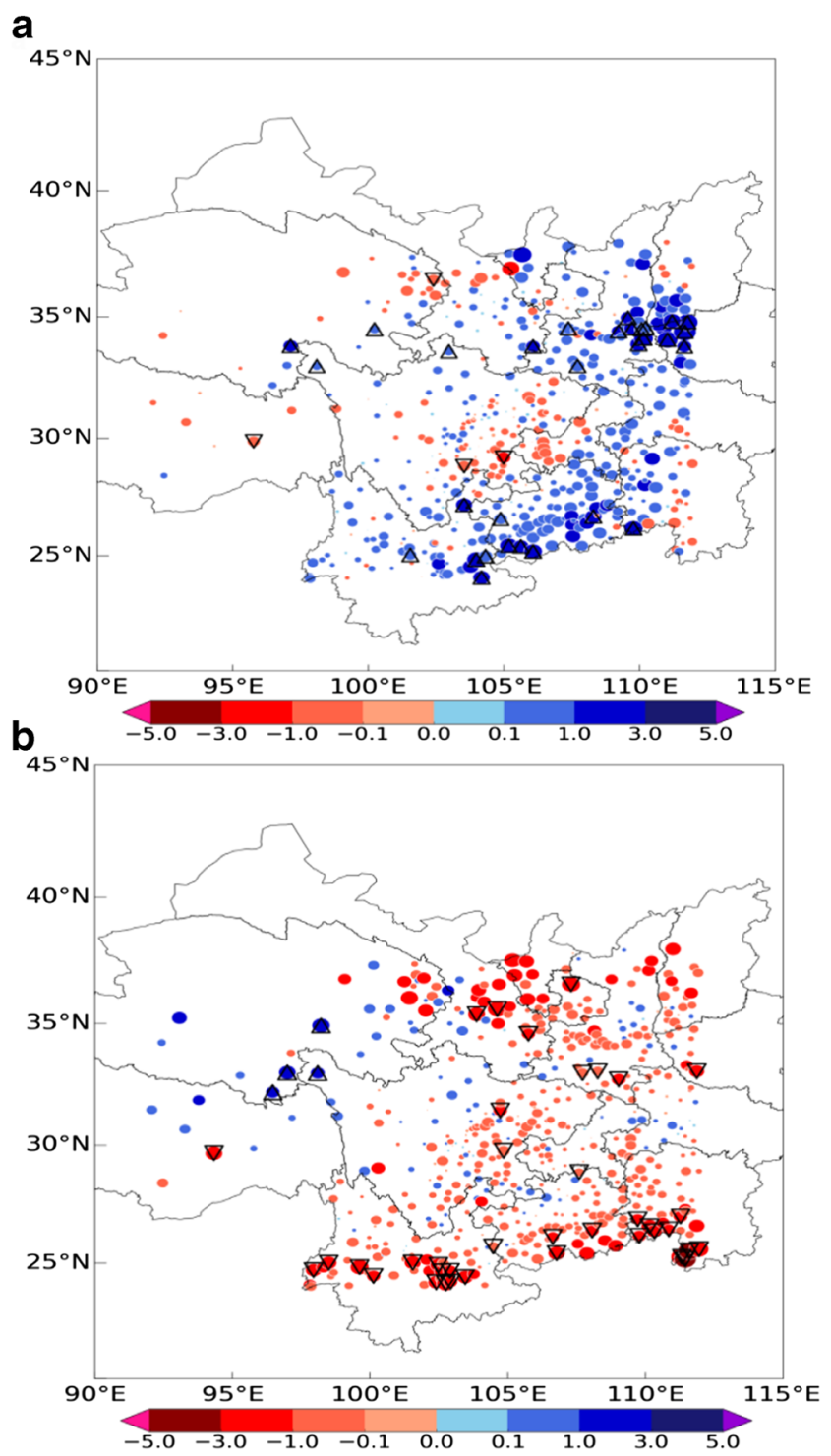

Fig. 5 Same as in Fig. 3, but for $\mathbf{a}$ the beginning day and $\mathbf{b}$ the ending day of autumn rain of West China

amount are consistent with that of rainfall frequency but opposite to that of rainfall intensity in this region. Over western West China, consistent upward trends between the rainfall amount and intensity but opposite trends between the rainfall amount and frequency suggest a main contribution to the increase of rainfall amount from the increase in rainfall intensity.

\subsection{Onset and termination of autumn rain of West China}

Figure 4 displays the temporal variation of the beginning day and the ending day of autumn rain of West China during 1961-2014. On the average, there is an ascending trend with the rate of 0.25 days per decade for the beginning day. To the contrary, a declining trend with the rate of 0.40 days per decade is observed for the ending day. These results illustrate that autumn rain of West China tends to begin later and terminate earlier since the 1960s. As a consequence, the period of autumn rain of West China has shortened in the past decades. Regionally, as shown in Fig. 5, the later onset and earlier termination of autumn rainy season can be found over a majority of the stations, particularly in the southeastern and northeastern parts of West China.

In general, in recent decades, the rainfall amount and the number of rainy days tend to reduce, the rainfall intensity tends to strengthen, the autumn rainy season is inclined to begin later and end earlier and thus the period of autumn rain of West China becomes shorter, despite some differences in different regions.

\section{Precipitation-related extremes}

In this section, we turn to analyze the extreme property of autumn rain of West China from two aspects: one is absolute indices measured by the maximum value of each year in autumn. These indices include the maximum daily rainfall, the greatest consecutive rainfall amount, and the longest consecutive rainy days. The other is percentile indices, including the extreme daily rainfall, the extreme consecutive rainfall, and the extreme consecutive rainfall process, measured by exceeding the percentile threshold (see Section 2 for the definition).

\subsection{Absolute indices}

The temporal change of the absolute indices, i.e., the maximum daily rainfall, the greatest consecutive rainfall amount, and the longest consecutive rainy days in autumn, is shown in Fig. 6a. For the average of the West China region, the maximum daily rainfall exhibits a tendency toward decrease at a rate of $0.22 \mathrm{~mm}$ per decade from 1961 to 2014. The greatest consecutive rainfall amount has also reduced at a rate of $2.5 \mathrm{~mm}$ per decade. Similarly, a significant decrease is detected in the longest consecutive rainy days. The decreasing trend is 0.5 days per decade. During the longest consecutive precipitation process, the accumulative rainfall amount has decreased at a rate of $2.3 \mathrm{~mm}$ per decade while the mean rainfall intensity has intensified at a rate of $0.2 \mathrm{~mm} /$ day per decade (Fig. 6b), also suggesting a major contribution of the rainy days to the decrease of rainfall amount.

On the regional scale, relatively large discrepancy exists in the change of the maximum daily rainfall. There are $58 \%$ of the stations showing a decreasing trend and $42 \%$ of the stations showing an increasing trend (Fig. 7a). The reduction of the greatest consecutive rainfall amount is more consistent. Seventy-three percent of the stations witness a decreasing tendency (Fig. 7b). For the change of 
Fig. 6 Same as in Fig. 2, but for a the maximum daily rainfall, the longest consecutive rainy days, and the greatest consecutive rainfall amount and for $\mathbf{b}$ the rainfall amount and intensity in the longest consecutive precipitation process

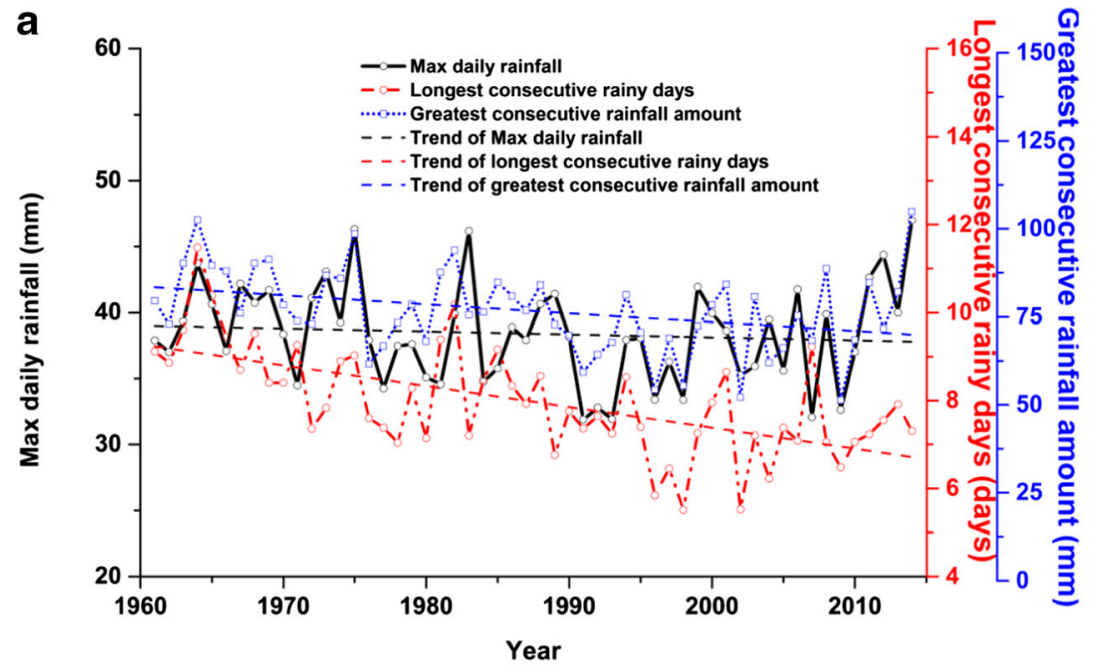

b

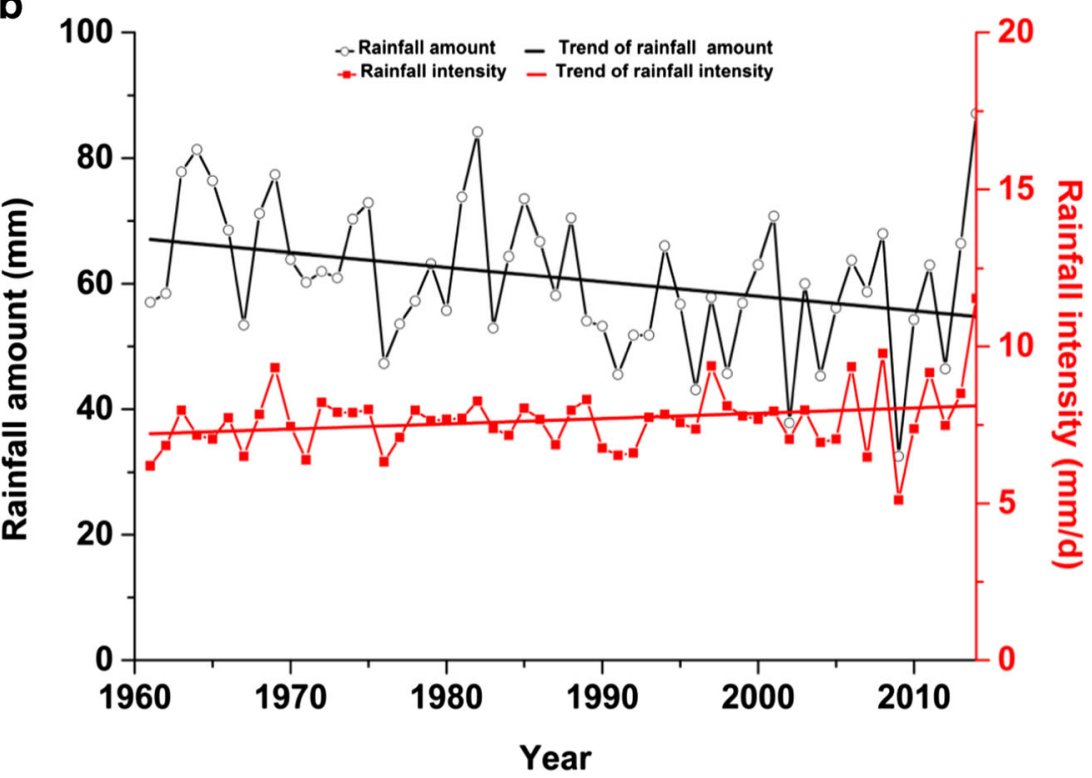

the longest consecutive rainy days (Fig. 7c), we can notice a widespread distribution of decreasing trends. To be specific, $88 \%$ of the stations show a decreasing trend above 0.1 days per decade, out of which 202 stations are significant at the $95 \%$ confidence level.

\subsection{Percentile indices}

Figure 8 shows the temporal change in the frequencies of the extreme daily rainfall, the extreme consecutive rainfall, and the extreme consecutive rainfall process. On the average of the West China region, they all delineate downward trends during the period of 1961-2014. The decreasing trends for the occurrence of the extreme daily rainfall, the extreme consecutive rainfall, and the extreme consecutive rainfall process are $0.1,0.1$, and 0.2 times per decade, respectively. On the regional scale, the reduction in the frequency of the extreme daily precipitation can be observed over 362 stations. The increasing trends above 0.1 times per decade are mainly over the western part of West China (Fig. 9a). The occurrence of the extreme consecutive rainfall becomes less frequent over 431 stations which are mainly located in the eastern part of West China (Fig. 9b). The decrease in the frequency of the extreme consecutive rainfall process is the most pronounced among the three percentile indices. More than half of the stations show significant trends above the $95 \%$ confidence level (Fig. 9c).

Changes of the accumulative rainfall amount and the mean rainfall intensity during the extreme consecutive rainfall processes are further displayed in Fig. 10. It is evident that there is a widespread decreasing in accumulative rainfall amount in West China. In total, 432 stations exhibit downward trends, 103 stations of which are significant at the $95 \%$ confidence level (Fig. 10a). However, changes of 


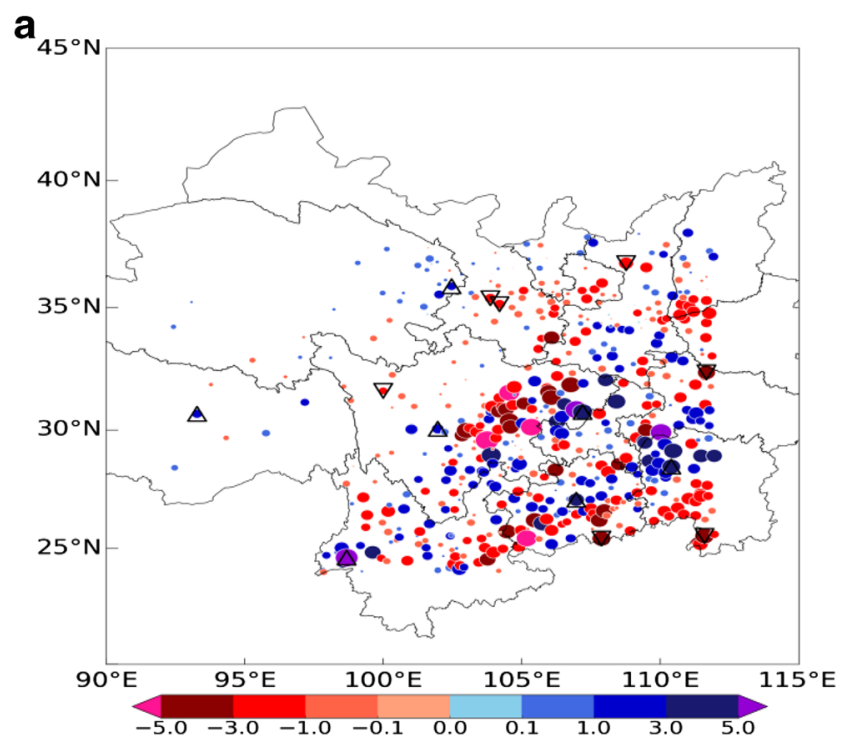

$\mathbf{b}_{4}$

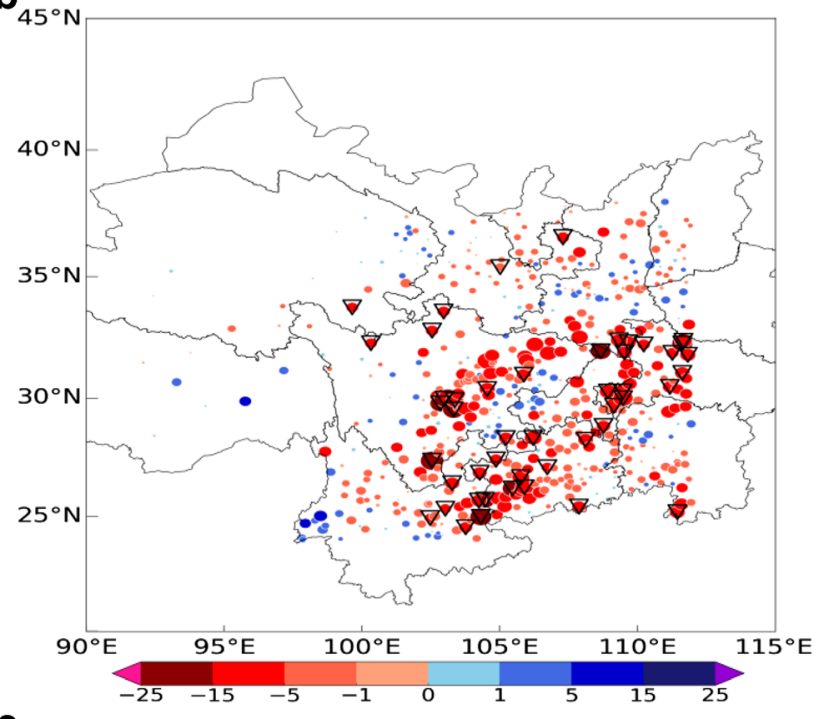

$C_{45}$

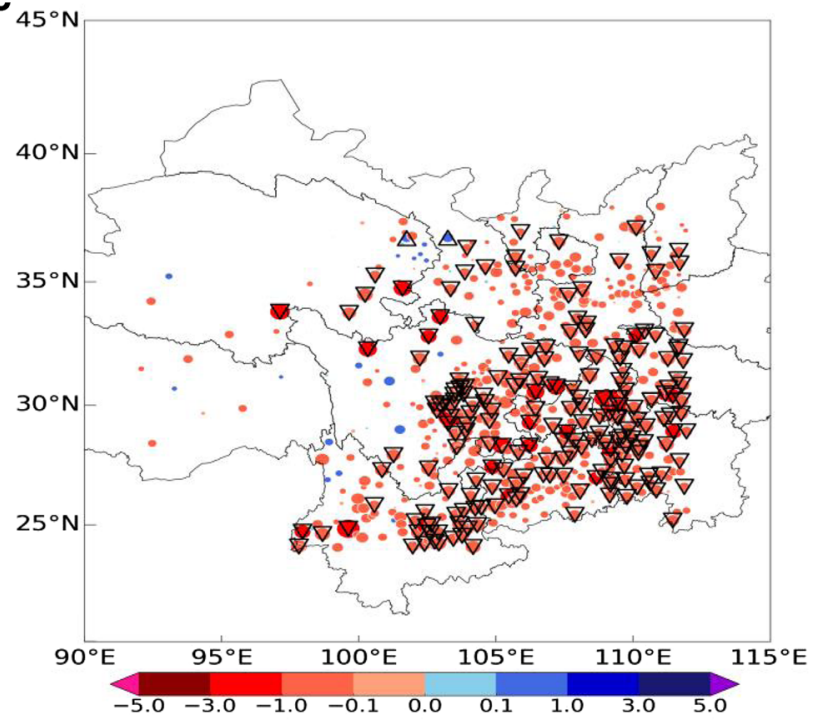

Fig. 7 Same as in Fig. 3, but for a the maximum daily rainfall $(\mathrm{mm} /$ 10 years), b the greatest consecutive rainfall amount ( $\mathrm{mm} / 10$ years), and $\mathbf{c}$ the longest consecutive rainy days (days/10 years)

the mean rainfall intensity are less consistent. It has increased over 340 stations and decreased over 182 stations (Fig. 10b). Regionally averaged, the accumulative amount has reduced and the mean intensity has strengthened (Fig. 11). Their respective rates are $-7.8 \mathrm{~mm}$ per decade and $0.1 \mathrm{~mm} /$ day per decade. Combined with the result shown in Fig. 8, it can be deduced that the decrease of accumulative amount during the extreme rainfall processes is mainly due to the decrease in the frequency of the extreme consecutive rainfall events.

In brief, the extremes of daily precipitation, consecutive precipitation, and consecutive precipitation process have all decreased in recent decades, especially in the eastern part of West China. Such decreasing trends in extreme indices are consistent with that of total precipitation amount. The correlation coefficients between the precipitation extreme indices and the total precipitation are higher than 0.7 , significant at the $99 \%$ confidence level. The decreases of the precipitation extreme indices in recent decades indicate a weakening of the extreme property of autumn rain of West China.

\section{Discussion}

Water vapor condition and atmospheric stability are essential to the occurrence of precipitation. More water vapor supply and more unstable atmospheric stratification are favorable for the increase of precipitation, and vice versa. Thus, we examine changes of the two factors in order to explore possible mechanism for changes of autumn rain of West China in recent decades.

Figure 12a shows the spatial distribution of liner trends of $850 \mathrm{hPa}$ meridional winds during 1961-2014. Clearly, significant negative trends are observed in most of West China, particularly in its eastern part. This result indicates that the southerly has weakened in the past decades. The weakening of the southerly tends to weaken the transporting of warm and moist water vapor from the south to the targeted region. As shown in Fig. 12b, we do notice significant weakening trends of the meridional water vapor transport over eastern West China. The water vapor transport is crucial to the moisture supply for intense precipitation locally. Meanwhile, the local precipitable water content is reduced (Fig. 12c). These changes are unfavorable for the occurrence of rainfall. Thus, the rainfall and related extremes have decreased in eastern West China since the 1960s. On the contrary, an increasing trend in $850 \mathrm{hPa}$ meridional wind and water vapor transport appears over the southwestern part of West China, 
Fig. 8 Same as in Fig. 2, but for the frequency of the extreme daily rainfall, the extreme consecutive rainfall, and the extreme consecutive rainfall process

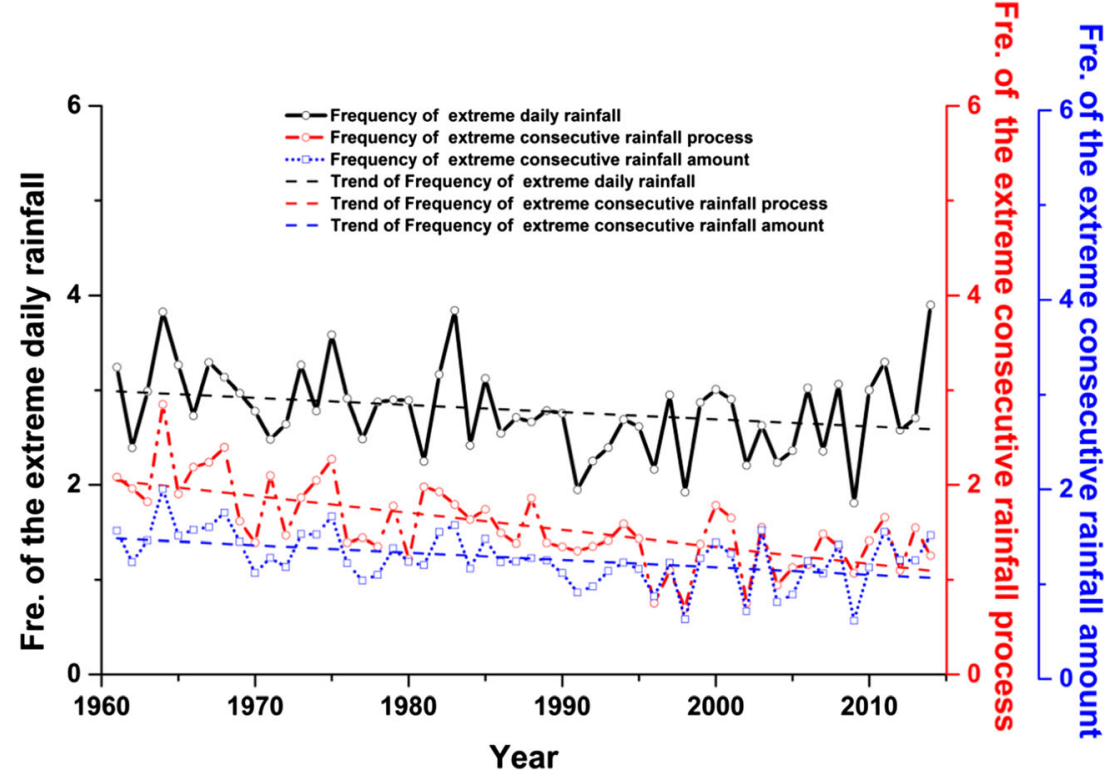

thereby increasing precipitable water content and providing sufficient water vapor for the increase of rainfall in this region.

Atmospheric stability, a dynamic condition for rainfall and related extremes, can be measured by the $K$ index which has been widely used in meteorological operations. The $K$ index is defined as $K=\left(T_{850}-T_{500}\right)+T_{\mathrm{d} 850}-(T-$ $T_{\mathrm{d}}{ }_{700}$, where $T$ is air temperature, $T_{\mathrm{d}}$ is dew point temperature, and subscripts 850,700 , and 500 represent pressure levels. A larger $K$ index corresponds to more unstable atmospheric stratification and favors more rainfall. Seen from Fig. 12d, there are significant decreasing trends for the $K$ index in the eastern part of West China. The decrease of the $K$ index indicates that atmospheric stratification in this region become less unstable from 1961 to 2014. Such a change tends to inhibit the development of the ascending motion of water vapor, unfavorable for the occurrence of rainfall. Thus, the rainfall decreases in eastern West China. In contrast, the increasing trends of the $K$ index in southwestern West China indicate more unstable atmospheric stratification, beneficial for the increase of local rainfall.

Considering West China as a whole, the $850-\mathrm{hPa}$ meridional wind, the meridional water vapor transport flux, the precipitable water content, and the $K$ index have decreased at the rates of $0.34 \mathrm{~m} \mathrm{~s}^{-1}, 6.15 \mathrm{~kg} \mathrm{~m}^{-1} \mathrm{~s}^{-1}$, $0.23 \mathrm{~kg}$, and $0.25{ }^{\circ} \mathrm{C}$ per decade (all significant at the $95 \%$ confidence level), respectively, since the 1960s. All of these changes provide unfavorable conditions for the occurrence of rainfall, consequently resulting in a decrease of autumn rainfall in West China. Therefore, decreases in water vapor supply and atmospheric unstable stratification may be responsible for the decrease of autumn rainfall and related extremes in West China during the past decades. Note that this study just focused on the linear trends in autumn rain of West China. As shown in Figs. 2, 6, and 8 , the precipitation indices did not change in a monotonous way during the analysis period. Their temporal changes and the influence of water vapor supply at other time scales (for instance, at the interdecadal time scale) deserves further investigation, but this subject is beyond the scope of the present discussion.

\section{Summary}

Based on the observed daily precipitation data from 524 meteorological stations for the period of 1961-2014, this study performed a detailed analysis on the secular change in autumn rain of West China. The main findings are summarized as follows:

(1) The amount and frequency of autumn rainfall have reduced for the average of West China, while the mean rainfall intensity has intensified since the 1960s. Besides, the autumn rainy season in general tends to start later and end earlier, and hence, the period of autumn rain of West China has shortened in recent decades. Regionally, the autumn rainfall has decreased in the eastern part but increased in the western part, the rainfall intensity has strengthened in most regions, and the rainy days have decreased almost in the entire region. In general, the decrease of rainfall amount over eastern West China is mainly due to the decrease in rainfall frequency, and the increase of rainfall amount over western West China is mainly due to the increase in rainfall intensity. 


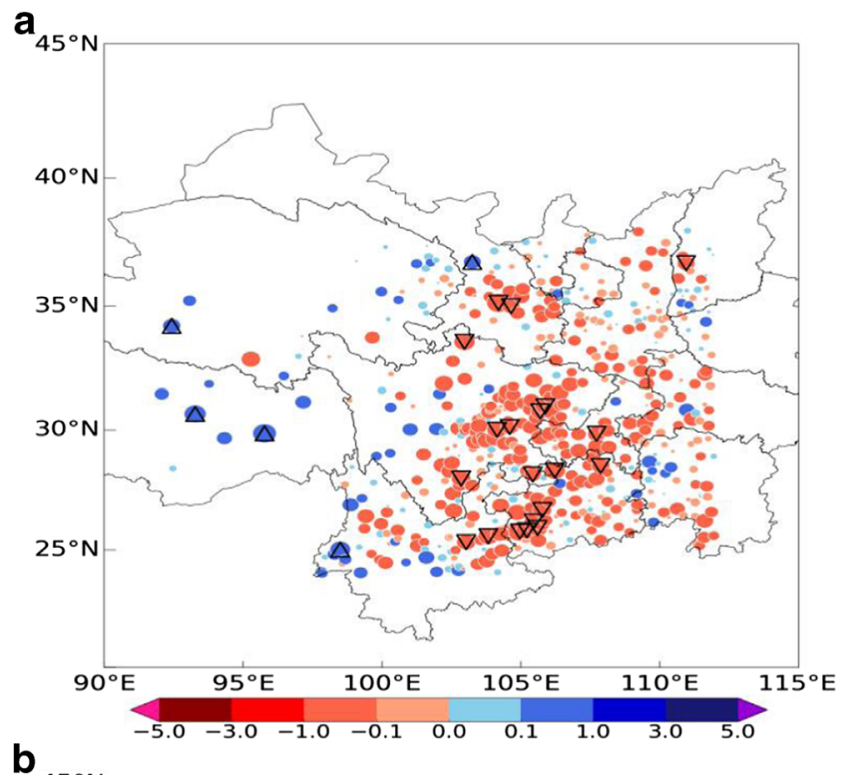

b

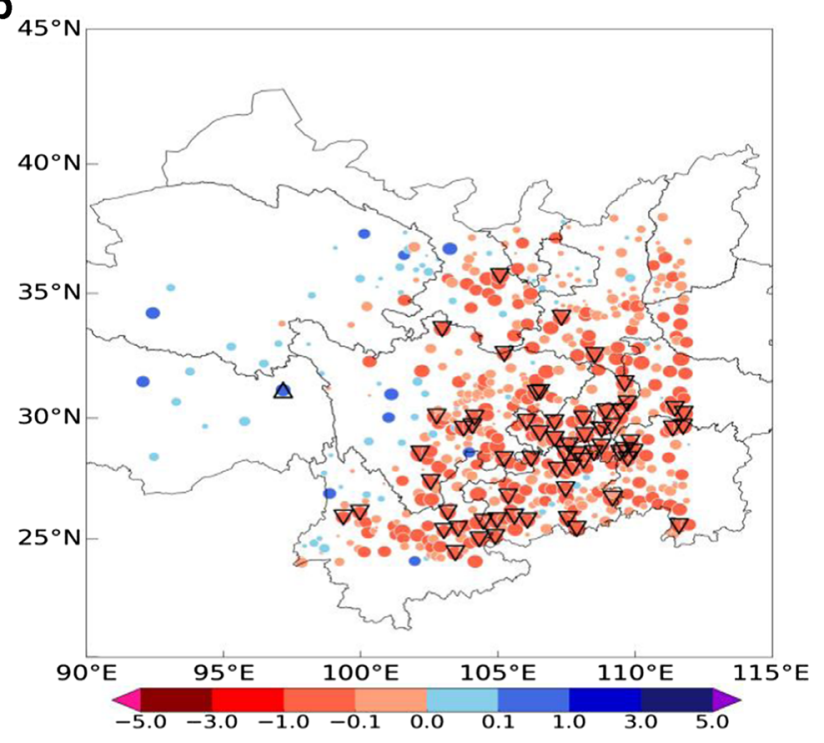

a

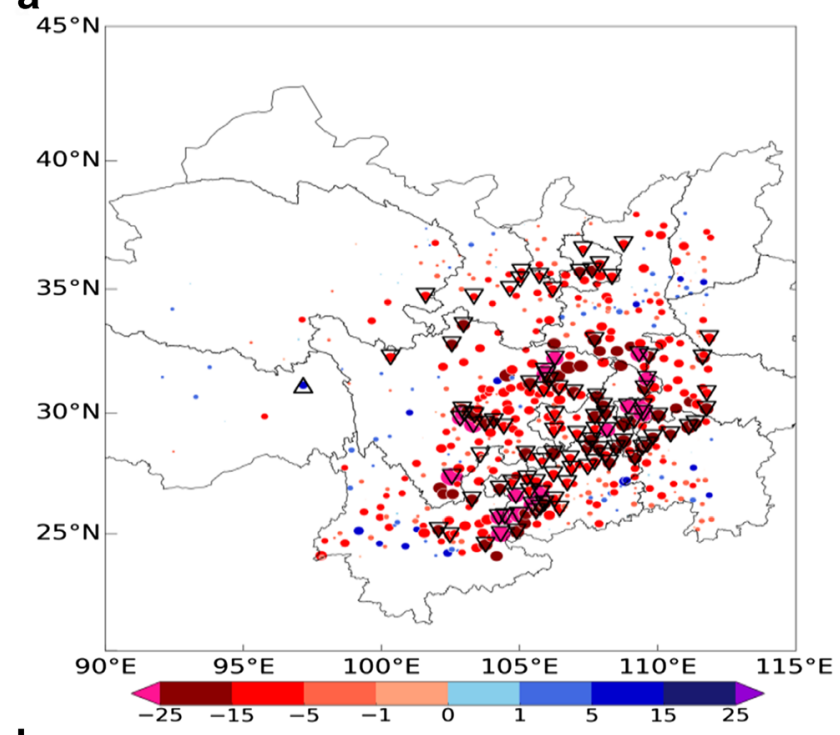

b

9 Same as in Fig. 3, but for the frequency (times/10 years) of a the extreme daily rainfall, $\mathbf{b}$ the extreme consecutive rainfall, and $\mathbf{c}$ the extreme consecutive rainfall process

(2) The maximum daily precipitation, the greatest consecutive precipitation amount, and the longest consecutive precipitation days averaged over West China all show a significant decreasing trend since the 1960s. The frequencies of the extreme daily precipitation, consecutive precipitation, and precipitation process have also reduced consistently. Therefore, the extreme property of autumn rain of West China appears to weaken to some degree. Nevertheless, the mean rainfall intensity during the extreme precipitation
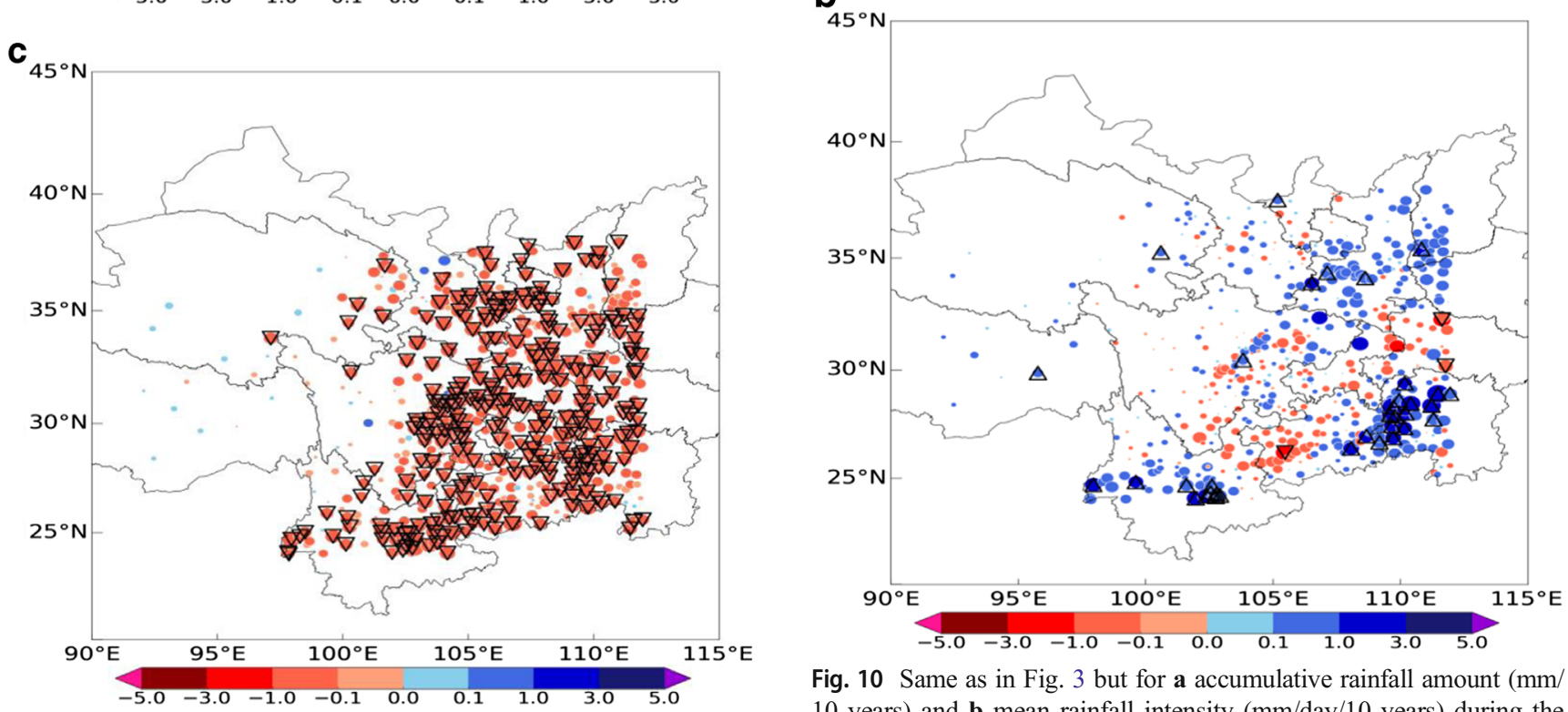

Fig. 10 Same as in Fig. 3 but for a accumulative rainfall amount (mm/ 10 years) and $\mathbf{b}$ mean rainfall intensity ( $\mathrm{mm} /$ day/10 years) during the extreme consecutive precipitation processes 
Fig. 11 Same as in Fig. 2, but for accumulative rainfall amount and mean rainfall intensity during the extreme consecutive precipitation processes

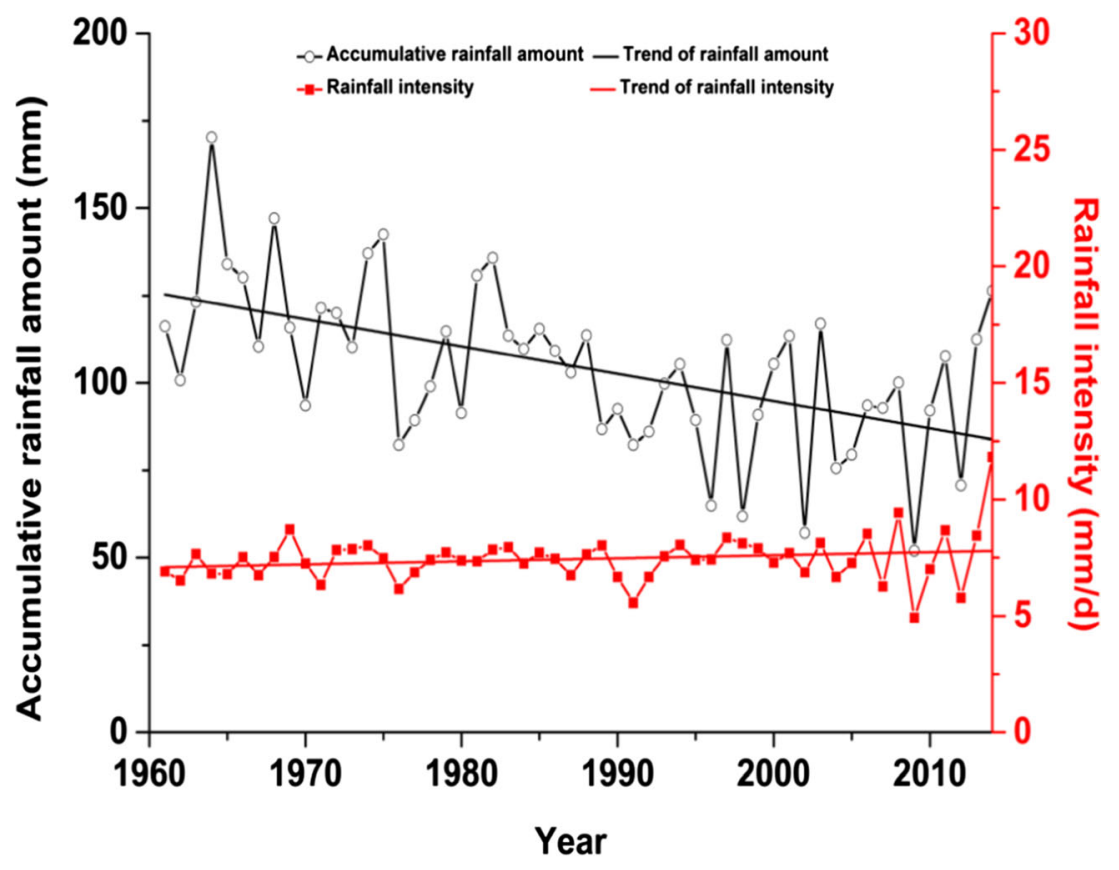

processes has increased. There are also some differences in their changes over different regions.
Further study reveals that changes of autumn rain of West China are closely connected to the changes in water vapor and
Fig. 12 Linear trends of a $850 \mathrm{hPa}$ meridional wind $\left(\mathrm{m} \mathrm{s}^{-1}\right.$ ) 10 years), $\mathbf{b}$ meridional water vapor transport flux vertically integrated from 1000 to $300 \mathrm{hPa}$ ( $\mathrm{kg} \mathrm{m}^{-1} \mathrm{~s}^{-1} / 10$ years), c precipitable water ( $\mathrm{kg} / 10$ years), and $\mathbf{d} K$ index $\left({ }^{\circ} \mathrm{C} / 10\right.$ years $)$ during autumn of 1961-2014. Areas above the $95 \%$ confidence level are shaded
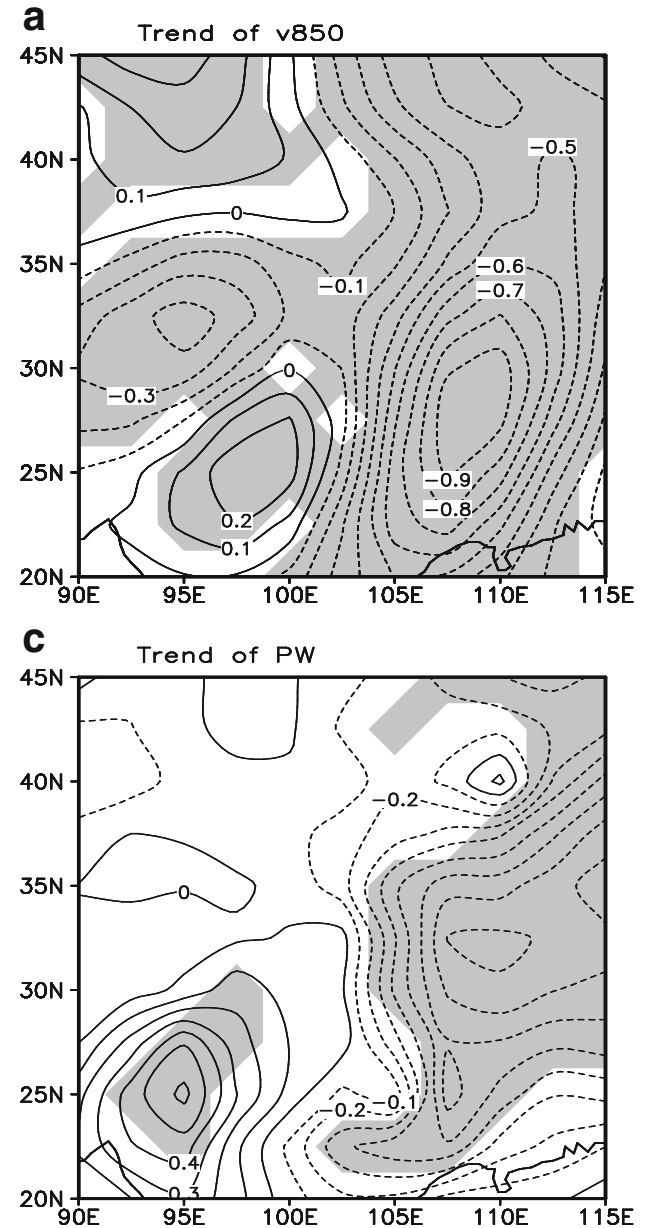
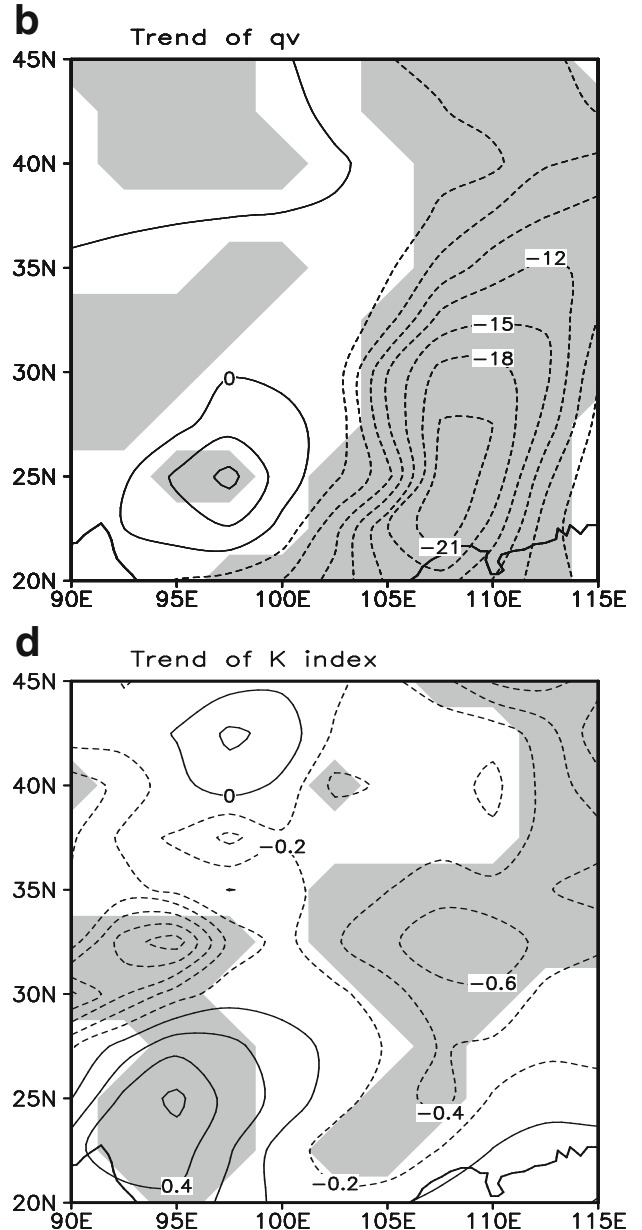
Fig. 13 a Correlations between the rainfall amount averaged over West China and $500 \mathrm{hPa}$ geopotential height during autumn of 1961-2014. Areas above the $95 \%$ confidence level are shaded. b Time series (solid line) and corresponding linear trend (dashed line) of the Lake Balkhash trough index (m) defined as area-averaged geopotential height at $500 \mathrm{hPa}$ over the rectangle region shown in a during autumn of 1961-2014
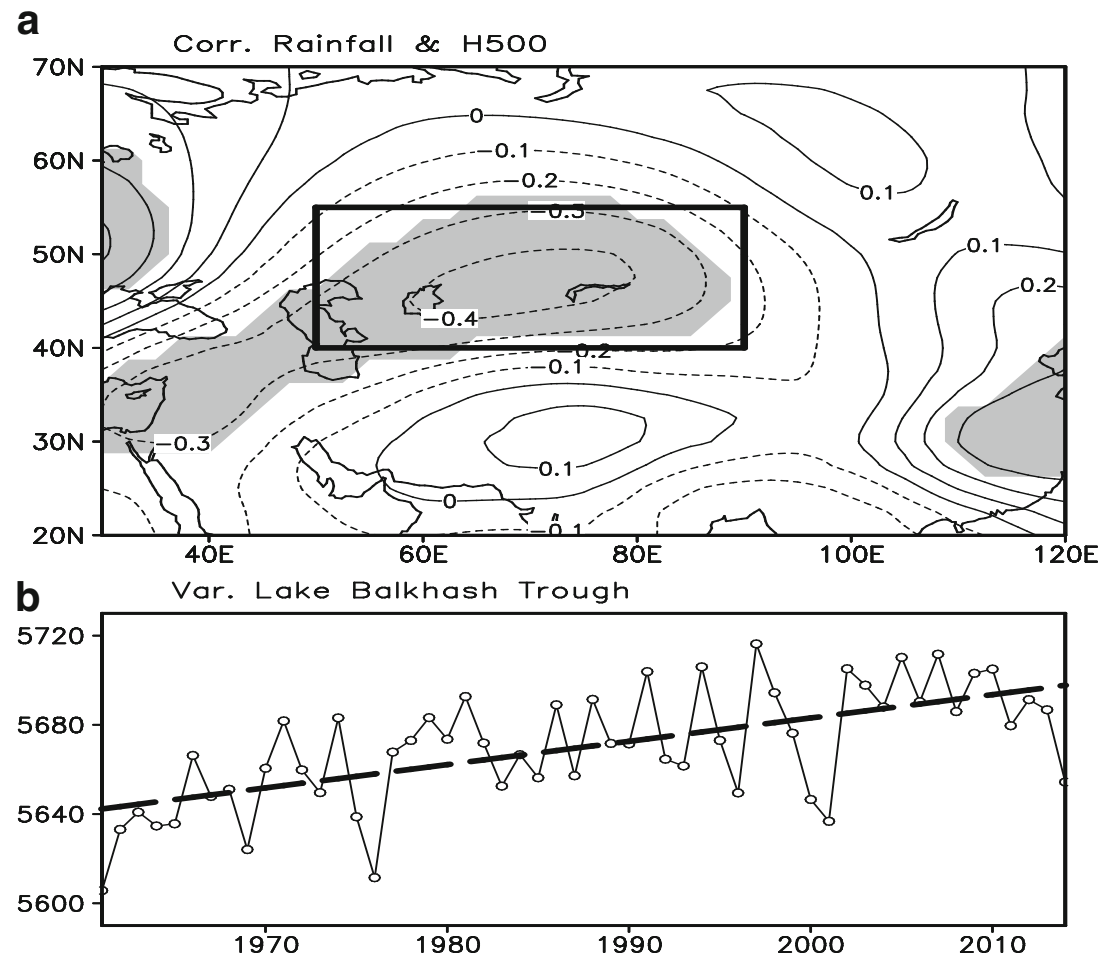

atmospheric stability. In the past decades, the water vapor supply has decreased in eastern West China. Meanwhile, the atmospheric stratification has become less unstable. These changes are unfavorable for the occurrence of precipitation and consequently decrease autumn rainfall and related extremes in eastern West China. The opposite change with the increase in water vapor supply and atmospheric unstable stratification over western West China provides a favorable background for the increase of local rainfall.

Certainly, above physical explanation is just from the perspective of local changes in moisture and dynamic conditions. Large-scale atmospheric circulation factors and external forcings may also play important roles in changes of autumn rain of West China. For instance, the trough over Lake Balkhash is documented to have a close relationship with autumn rain of West China. A deeper trough corresponds to more autumn rainfall in West China, and vice versa (Bai and Dong 2004, also see Fig. 13a). From 1961 to 2014, the Lake Balkhash trough shows a significant weakening trend (Fig. 13b). This weakening of the Lake Balkhash trough is expected to reduce autumn rainfall in West China. Therefore, more in-depth analyses are needed in the future work to clarify other physical processes and dynamic mechanisms responsible for changes of autumn rain of West China. Moreover, study is also required to quantify to what an extent the change of autumn rain of West China under global warming is attributed to anthropogenic forcing. Besides, some previous studies indicated that the onset and termination of autumn rain of West China are related to the transition of summer monsoon to winter monsoon (Ding 2007; Ding and Wang 2008; Yuan and Liu 2013). However, due to its nature of intraseasonal variability and complexity, why the autumn rainy season starts later and ends earlier is still an open issue. To get a full picture to understand changes of autumn rain of West China, these issues should be addressed in the future.

Acknowledgments This research was jointly supported by the National Natural Science Foundation (41675069), the National Key Research and Development Program of China (2016YFA0600701), the Key Technical Development Program for Predictable Service of China Meteorological Administration (YBGJXM (2017) 05), and the Youth Foundation of Chongqing Meteorological Bureau (QNJJ-201603).

Open Access This article is distributed under the terms of the Creative Commons Attribution 4.0 International License (http:// creativecommons.org/licenses/by/4.0/), which permits unrestricted use, distribution, and reproduction in any medium, provided you give appropriate credit to the original author(s) and the source, provide a link to the Creative Commons license, and indicate if changes were made.

\section{References}

Alexander LV, Zhang X, Peterson TC, Caesar J, Gleason B, Klein Tank AMG, Haylock M, Collins D, Trewin B, Rahimzadeh F, Tagipour A, Rupa Kumar K, Revadekar J, Griffiths G, Vincent L, Stephenson DB, Burn J, Aguilar E, Brunet M, Taylor M, New M, Zhai P, Rusticucci M, Vazquez-Aguirre JL (2006) Global observed changes in daily climate extremes of temperature and precipitation. J Geophys Res 111(D5): D05109. https://doi.org/10.1029/2005JD006290

Bai H, Dong W (2004) Climate features and formation causes of autumn rain over Southwest China. Plateau Meteorol 23(6):884-889

Bai A, Zhai P, Liu X (2007) On climatology and trends in wet spell of China. Theor Appl Climatol 88:137-148

Camberlin P, Philippon N (2002) The East African march-may rainy season: associated atmospheric dynamics and predictability over 
the 1968-97 period. J Clim 15(9):1002-1018. https://doi.org/10. 1175/1520-0442(2002)015<1002:TEAMMR >2.0.CO;2

Ding Y (2007) The variability of the Asian summer monsoon. J Meteorol Soc Jpn 85:21-54

Ding Y, Wang Z (2008) A study of rainy season in China. Meteorog Atmos Phys 16(3):121-138

Ding Y, Wang Z, Sun Y (2008) Inter-decadal variation of the summer precipitation in East China and its association with decreasing Asian summer monsoon. Part I: observed evidences. Int J Climatol 28(9): 1139-1161. https://doi.org/10.1002/Joc.1615, 2008

Easterling DR, Meehl GA, Parmesan C, Changnon SA, Karl TR, Mearns LO (2000) Climate extremes: observations, modeling, and impacts. Science 289:2067-2074

Fan K, Xu Z, Tian B (2014) Has the intensity of the interannual variability in summer rainfall over South China remarkably increased? Meteorog Atmos Phys 124(1-2):23-32. https://doi.org/10.1007/ s00703-013-0301-5

Feng S, Nadarajah S, Hu Q (2007) Modeling annual extreme precipitation in China using the generalized extreme value distribution. J Meteorol Soc Jpn 85(5):599-613. https://doi.org/10.2151/jmsj.85. 599

Frich P, Alexander LV, Della-Marta P, Gleason B, Haylock M, Klein Tank A, Peterson T (2002) Observed coherent changes in climatic extremes during the second half of the 20th century. Clim Res 19: 193-212. https://doi.org/10.3354/cr019193

Gong DY, Ho CH (2002) Shift in the summer rainfall over the Yangtze River valley in the late 1970s. Geophys Res Lett 29(10):1436-78-4. https://doi.org/10.1029/2001g1014523

IPCC (2013) Climate change 2013: The physical science basis. In: Stocker TF, Qin D, Plattner G-K, Tignor M, Allen SK, Boschung J, Nauels A, Xia Y, Bex V and Midgley PM (eds) Contribution of working group I to the fifth assessment report of the intergovernmental panel on climate change. Cambridge University Press, Cambridge and New York, pp 1535

Kalnay E, Kanamitsu M, Kistler R, Collins W, Deaven D, Gandin L, Iredell M, Saha S, White G, Woollen J, Zhu Y, Leetmaa A, Reynolds R, Chelliah M, Ebisuzaki W, Higgins W, Janowiak J, Mo KC, Ropelewski C, Wang J, Jenne R, Joseph D (1996) The NCEP/NCAR 40-year reanalysis project. Bull Am Meteorol Soc 77(3):437-471. https://doi.org/10.1175/1520-0477(1996) 077<0437:TNYRP>2.0.CO;2

Kruger AC, Sekele SS (2013) Trends in extreme temperature indices in South Africa: 1962-2009. Int J Climatol 33(3):661-676. https://doi. org/10.1002/joc.3455

Liu B, Xu M, Henderso M, Qi Y (2005) Observed trends of precipitation amount, frequency, and intensity in China, 1960-2000. J Geophy Res 110(D8):D08103. https://doi.org/10.1029/2004JD004864

Min SK, Zhang X, Zwiers FW, Hegerl GC (2011) Human contribution to more intense precipitation extremes. Nature 470(7334):378-381. https://doi.org/10.1038/nature09763

Orlowsky B, Seneviratne SI (2012) Global changes in extreme events: regional and seasonal dimension. Clim Chang 110(3-4):669-696. https://doi.org/10.1007/s10584-011-0122-9

Qian W, Qin A (2008) Precipitation division and climate shift in China from 1960 to 2000. Theor Appl Climatol 93(1-2):1-17. https://doi. org/10.1007/s00704-007-0330-4

Qian W, Fu J, Yan Z (2007) Decrease of light rain events in summer associated with a warming environment in China during 19612005. Geophys Res Lett 34(11):L11705. https://doi.org/10.1029/ 2007GL029631

Rusticucci M (2012) Observed and simulated variability of extreme temperature events over South America. Atmos Res 106:1-17. https:// doi.org/10.1016/j.atmosres.2011.11.001

Sun JQ, Ao J (2013) Changes in precipitation and extreme precipitation in a warming environment in China. Chin Sci Bull 58(12):1395-1401. https://doi.org/10.1007/s11434-012-5542-Z
Wang B, Jhun JG, Moon BK (2007) Variability and singularity of Seoul, South Korea, rainy season (1778-2004). J Clim 20(11):2572-2580. https://doi.org/10.1175/JCLI4123.1

Wang HJ, Sun JQ, Chen HP, Zhu YL, Zhang Y, Jiang DB, Lang XM, Fan K, ET Y, Yang S (2012) Extreme climate in China: facts, simulation and projection. Meteorol Z 21(3):279-304. https://doi.org/10.1127/ 0941-2948/2012/0330

Wang T, Wang H, Ottera OH, Gao Y, Suo L, Furevik T, Yu L (2013) Anthropogenic agent implicated as a prime driver of shift in precipitation in eastern China in the late 1970s. Atmos Chem Phys 13(24): 12433-12450. https://doi.org/10.5194/acp-13-12433-2013

Wang Y, Zhou B, Qin D, Wu J, Gao R, Song L (2017) Changes in mean and extreme temperature and precipitation over the arid region of northwestern China: observation and projection. Adv Atmos Sci 34(3):287-305. https://doi.org/10.1007/s00376-016-6160-5

Wu R, Chen L (1998) Decadal variation of summer rainfall in the Yangtze-Huaihe River valley and its relationship to atmospheric circulation anomalies over East Asia and western North Pacific. Adv Atmos Sci 15:510-522

Wu R, Wen Z, Yang S, Li Y (2010) An interdecadal change in Southern China summer rainfall around 1992/93. J Clim 23(9):2389-2403. https://doi.org/10.1175/2009JCLI3336.1

Wu J, Zhou B, Xu Y (2015) Response of precipitation and its extremes over China to warming: CMIP5 simulation and projection. Chin J Geophys 58(5):461-473

Xu Z, Fan K, Wang H (2015) Decadal variation of summer precipitation over China and associated atmospheric circulation after the late 1990s. J Clim 28(10):4086-4106. https://doi.org/10.1175/JCLI-D-14-00464.1

Yan Z, Jones PD, Davies TD, Moberg A, Bergstrom H, Camuffo D, Cocheo C, Maugeri M, Demaree GR, Verhoeve T, Thoen E, Barriendos M, Rodriguez R, Martin-Vide J, Yang C (2002) Trends of extreme temperatures in Europe and China based on daily observations. Clim Chang 53(1/3):355-392. https://doi.org/10.1023/A:1014939413284

Yao C, Yang S, Qian W, Lin Z, Wen M (2008) Regional summer precipitation events in Asia and their changes in the past decades. J Geophys Res 113(D17):D17107. https://doi.org/10.1029/ 2007JD009603

You Q, Kang S, Aguilar E, Yan Y (2008) Changes in daily climate extremes in the eastern and central Tibetan Plateau during 19612005. J Geophys Res 113(D7):D07101. https://doi.org/10.1029/ 2007JD009389

Yuan X, Liu XF (2013) Onset-withdrawal dates of autumn persistent rains over Western China and the associated autumn to winter evolution of the atmospheric circulation. Acta Meteorol Sin 71(5):913-924

Zhai P, Sun A, Ren F, Liu X, Gao B, Zhang Q (1999) Changes of climate extremes in China. Climate Change 42(1):203-218. https://doi.org/ 10.1023/A: 1005428602279

Zhai P, Zhang X, Wan H, Pan X (2005) Trends in total precipitation and frequency of daily precipitation extremes over China. J Clim 18(7): 1096-1108. https://doi.org/10.1175/JCLI-3318.1

Zhang Q, Xu C, Zhang Z, Chen Y, Liu C (2009) Spatial and temporal variability of precipitation over China, 1951-2005. Theor Appl Climatol 95(1):53-56. https://doi.org/10.1007/s00704-007-0375-4

Zhao P, Yang S, Yu RC (2010) Long-term changes in rainfall over Eastern China and large-scale atmospheric circulation associated with recent global warming. J Clim 23(6):1544-1562. https://doi.org/10.1175/ 2009jcli2660.1

Zhou B, Xu Y, Wu J, Dong S, Shi Y (2016) Changes in temperature and precipitation extreme indices over China: analysis of a highresolution grid dataset. Int J Climatol 36(3):1051-1066. https://doi. org/10.1002/joc. 4400

Zhu Y, Wang H, Zhou W, Ma JH (2011) Recent changes in the summer precipitation pattern in East China and the background circulation. Clim Dyn 36(7-8):1463-1473. https://doi.org/10.1007/s00382-0100852-9 